Nunt. Antiquus, Belo Horizonte, v. 16, n. 2, p. 111-132, 2020

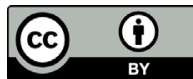

\title{
O speculum de Filemácia na Mostellaria de Plauto e o jogo metateatral entre os papéis das meretrizes na comédia palliata
}

\author{
Philematium' speculum in Plautus' Mostellaria and the \\ Metatheatrical Play Involving the Stock Character \\ of the meretrix in the palliatae
}

\author{
Carol Martins da Rocha \\ Universidade Federal de Juiz de Fora (UFJF), Juiz de Fora, Minas Gerais / Brasil \\ carol.rocha@ufjf.edu.br \\ https://orcid.org/0000-0002-7510-7588
}

Resumo: Este artigo trata mais centralmente da participação da meretriz Filemácia (Philematium) e de sua escrava, Escafa (Scapha), na peça Mostellaria, de Plauto (III - II a.C.), para entender o modo como a interação entre tais personagens traz à tona nuanças do tipo cômico que elas representam. As duas personagens femininas figuram em cena apenas no primeiro ato dessa comédia, num diálogo que se estende entre os versos 157 e 312 . Este texto, levando em consideração, sobretudo, aspectos considerados metateatrais, procura apontar como, apesar da breve participação de tais personagens, é importante olhar com atenção para elementos da cena, em que Filemácia e Escafa conversam. Na passagem, que envolve o uso de um espelho, estão em jogo os diferentes papéis que as meretrizes costumam exercer na comédia palliata e, também, alusões a importantes aspectos cênicos do teatro antigo. As conclusões apontam para a maneira como as nuanças dos tipos cômicos afetam o entendimento do enredo como um todo e da ação das suas personagens, contribuindo para os efeitos cômicos presentes na peça.

Palavras-chave: Plauto; Mostellaria; meretrizes; metateatro.

Abstract: The primary interest of this paper is to observe the action of two personae in Plautus' Mostellaria, Philematium, a meretrix, and her ancilla, Scapha, and to understand the way their interaction makes the multiple nuances of this stock character evident. Both female characters appear, talking to each other, only in the first act of this comedy (v. 157 to 312). Considering some features that have been understood as metatheatrical, this essay attempts to point out the value of some elements in the 
aforementioned scene, despite its brevity. In the passage, it seems that the actions of these two characters, with the help of a mirror, throw light in the allusions to the different roles usually played by the meretrices in the fabula palliata, and also to significant scenic aspects of the ancient theatre. Some of the final thoughts discuss how our understanding of the plot and the acts of its characters are affected by the emerging nuances of the meretrix' stock character and how it amplifies the comical effects in the play.

Keywords: Plautus; Mostellaria; prostitutes; metatheatre.

\section{Introdução ${ }^{1}$}

À primeira vista, A comédia dos fantasmas (Mostellaria), peça de Tito Mácio Plauto (III - II a.C.), costuma chamar a atenção, ao menos dos leitores modernos, pela aparentemente inusitada menção a uma casa mal-assombrada por um fantasma. Esse aspecto fantasioso, no entanto, embora não se repita em nenhuma das outras peças supérstites da palliata, ${ }^{2}$ parece ter povoado a imaginação dos antigos gregos e romanos - lembremo-nos, apenas para ilustrar, da história do filósofo Atenodoro, narrada por Plínio o Jovem em uma de suas cartas (PLIN. Ep. 7, 27). ${ }^{3}$

\footnotetext{
${ }^{1}$ Agradeço ao parecerista anônimo pelas sugestões pontuais feitas durante a avaliação do texto. Uma tradução nossa de toda a terceira cena do primeiro ato de Mostellaria foi aceita para publicação no número 19 da revista Translatio, enquanto o processo editorial deste artigo estava em andamento.

${ }^{2}$ Segundo Ernout (PLAUTE, 2003, p. 13), conhecem-se apenas o título de três comédias gregas nomeadas Фá $\sigma \mu \alpha$ : uma de Teogneto (III a.C.), outra de Menandro (III a.C.) e a terceira de Filemão (III a.C.). Supõe-se, a partir da proposta de Ritschl, em seu estudo de 1845 (Parerga zu Plautus und Terenz), que esta última tenha sido o modelo para a peça plautina, ainda que o indício para tal afirmação - a saber, a menção a Dífilo no verso 1149 da peça - seja pouco confiável (cf. PLAUTE, 2003, p. 13).

${ }^{3}$ Em resumo, a história é a seguinte: um filósofo, chamado Atenodoro, chega a Atenas e vem a saber de uma casa para alugar a baixo preço. Desconfiado, Atenodoro investiga os motivos para tal situação e descobre que a casa tinha sido abandonada pela família que fora atormentada por um fantasma, fazendo barulhos de corrente. Tendo caído a noite, o filósofo se concentra em escrever, à espera da aparição, que, ao surgir, o chama até um espaço no jardim e some. No dia seguinte, o lugar indicado é cavado e ali se descobrem ossos presos a ferros. Assim que os restos mortais recebem um funeral adequado, a casa deixa de ser mal-assombrada. Para um levantamento mais completo sobre o tema dos espectros na literatura antiga, cf. Kemper (2010).
} 
O mote da casa mal-assombrada integra como refinado recurso o plano que Tranião, o escravo calejado (seruus callidus) da peça, prega no velho Teoprópides, pai de seu dono, o jovem Filólaques. O estratagema de Tranião consiste em convencer o senex de que o adulescens havia abandonado a casa em que moravam porque o fantasma de um hóspede assassinado pelo antigo proprietário dela havia lhe aparecido em sonho para revelar todo seu infortúnio e avisá-lo da maldição da casa (v. 431-531).

Apesar do merecido destaque da "participação" desse fantasma na peça, nosso foco nesta discussão é outro. Temos, dentre as personae de Mostellaria, além do já mencionado escravo, seu patrão e o senex Teoprópides, três personagens femininas: duas meretrizes ${ }^{4}$ - Filemácia (Philematium) e Délfia (Delphium) ${ }^{5}$ - e Escafa (Scapha), velha escrava, que outrora fora também meretriz. A participação delas é bastante reduzida: quando o plano de Tranião começa a ser posto em prática, elas não retornam mais ao palco. Filemácia e sua escrava, Escafa, personagens

\footnotetext{
${ }^{4}$ Fazemos aqui um breve parêntese quanto ao uso do termo "meretriz". Em artigo de 2015, Serena Witzke busca apontar como a escolha lexical na tradução dos termos meretrix, scortum e amica - usados para designar a prostituta das peças da palliata pode apagar ou relativizar o fato de que as moças ali representadas não são mulheres que optaram por ter como fonte de renda a prostituição, mas sim mulheres escravizadas para o trabalho sexual. Assim, cabe lembrar que, ainda que seja discutível o quão literalmente o teatro antigo ou de qualquer época representa a realidade em que está inserido (sobre a discussão, por exemplo, da relação estreita entre a noção de gênero sexual e a noção de gênero literário no contexto da comédia palliata, cf. Rocha (2015, p. 27-42), ao tratarmos da meretriz na comédia nova grega e romana, estamos nos referindo a mulheres que são representadas nessas condições. Vale mencionar ainda a afirmação de Hunter $(1989$, p. 92) de que os poetas cômicos romanos nem sempre faziam a distinção entre os diferentes tipos de prostitutas, importante para o contexto grego. Cf., no entanto, Cist. 331 e Poen. 265-270, em que se distinguem diferentes tipos dessas profissionais. Sobre os diversos termos latinos empregados para designar "prostituta", cf. Adams (1983).

${ }^{5}$ Ainda que mais de um nome próprio de prostituta nas peças de Plauto pertença ao gênero gramatical neutro - é o caso, por exemplo, dos nomes de Erotium, de Menecmos, e Phronesium, de Truculento -, preferimos adotar uma versão no feminino (que geralmente termina em -a no português) desses nomes em nossa tradução. Reina Pereira (PLAUTO, 2014), no entanto, adota "Filemácio" e "Délfio" ao traduzir o nome dessas personagens de Mostellaria.
} 
sobre as quais recai mais centralmente nossa atenção, figuram em cena apenas no primeiro ato da peça, entre os versos 157 e 312 .

Mas, ainda que o desenrolar do enredo de Mostellaria não dependa diretamente da ação dessas duas personagens, parece-nos que grande parte da trama está baseada em aspectos do comportamento das meretrizes, cuja postura já era conhecida pelo público da comédia palliata. Nosso argumento é de que tais aspectos constituem parte do pano de fundo para a cena, entre os versos 157 e 312, em que Filemácia e Escafa conversam, enquanto a jovem meretriz procura se enfeitar para seu amado. Observando o diálogo entre tais personagens, procuramos delinear dois fatores importantes para a construção do humor em Mostellaria. Para isso, divisamos e apontamos elementos característicos da comédia palliata, sobretudo os relacionados ao papel da meretriz, que são trazidos à tona na peça. Destacamos ainda o modo como, por meio da metateatralidade, a menção a comportamentos típicos das meretrizes produz efeitos de humor diversos. Afinal, parece ser fato que, na comédia nova grega e romana, antes de ter medo dos espíritos é preciso ter cuidado com os vivos.

\section{O tipo da meretrix na comédia palliata}

Como sabemos, a meretrix está presente na maior parte das peças da comédia nova romana. Das seis produções de Terêncio, destacam-se não somente a participação de Taís em Eunuco e Báquide em Hecyra, mas também o envolvimento de Báquide no enredo de Heautontimorumenos. Das vinte e uma peças plautinas, apenas cinco (a saber: Anfitrião, Aululária, Os cativos, Cásina e Trinumo) não apresentam meretrices no palco. ${ }^{6}$

\footnotetext{
${ }^{6}$ Como nos lembra Packman (1999), a depender da edição, pode variar a designação de tipos femininos nas listas denominadas dramatis personae, que, como sabemos, provém de uma época posterior à de Plauto (sobre a origem das listas de personagem, cf. discussão de Petersmann (PLAUTUS, 1973, p. 85) e Cardoso (2006, p. 88)). Um exemplo é o modo como Adelfásia e Anterástile d'O jovem cartaginês são designadas: segundo Packman (1999, p. 246), na edição de Lindsay, datada de 1903, elas são apresentadas como puellae. Já na edição de Ernout, de 1938, tais personagens são listadas como meretrices.
} 
No entanto, é interessante notar que, ainda que o tipo não esteja presente numa peça, ele, muitas vezes, não deixa de ser tematizado. Em Trinumo, personagens, como o jovem Lisíteles, combatem o desperdício do patrimônio familiar gerado em relações com meretrizes (Trin. 22375). Já n'Os cativos, peça de tema bélico, centrada em torno de confusão de identidades e relações entre pai, filho e escravos, ao se declarar, no prólogo, que essa comédia não tem semelhança com as demais, incluise no rol de personagens preteridos o tipo da meretriz. ${ }^{7}$ Esse é, a nosso ver, um indício da relevância que esse tipo de personagem costuma ter na comédia de Plauto e Terêncio.

Em termos gerais, as prostitutas na palliata costumam ser classificadas basicamente em dois tipos: de um lado, as prostitutas independentes (ou seja, que administram seu próprio ofício); de outro, as jovens que trabalham para um cafetão ou cafetina, ou que se iludem com as promessas de amor de seus companheiros. ${ }^{8} \mathrm{O}$ primeiro grupo abrange as prostitutas espertas e experientes, mas, por outro lado, percebidas como mercenárias e sem sentimento. Já na segunda categoria, teríamos as moças mais jovens, envolvidas numa relação amorosa com um rapaz por elas já apaixonado, ou, então, na expectativa de serem compradas ou libertadas de seu cafetão. Em termos de relação com o público, o último grupo - o das jovens meretrizes - é normalmente apresentado de forma mais simpática e atrativa, em oposição às meretrices do primeiro, que são caracterizadas como mulheres confiantes, ávidas por dinheiro e dominadoras. ${ }^{9}$

Tal comportamento estereotipado - que, vale lembrar, ganha nuanças nas diferentes peças da palliata - parece servir como pano de

\footnotetext{
${ }^{7}$ Sobre a presença de meretrizes e outras personagens femininas na palliata, cf. os estudos mais gerais sobre o teatro romano de Duckworth (1952), Manuwald (2011) e Dutsch, James e Konstan (2015). Mais especificamente sobre a obra plautina, cf. Dutsch (2008) e Rocha (2015).

${ }^{8}$ Duckworth (1952, p. 260) define esse segundo grupo como bonae meretrices. Sobre a divisão, em linhas gerais, desses dois tipos de prostitutas, cf. Duckworth (1952, p. 258-261) e ainda os comentários de Barsby (PLAUTUS, 1991 [1986], p. 97-98).

${ }^{9}$ Cf. Hunter (1989, p. 92). Sobre a caracterização geral das meretrizes em Plauto, cf., ainda, Ferreira (2013). Sobre aspectos relacionados ao discurso das meretrizes, cf. Rocha (2015, p. 80-84).
} 
fundo para o desenvolvimento da cena que escolhemos cotejar neste texto. No diálogo entre Filemácia, uma jovem meretriz, que está, ao menos alegadamente, apaixonada por Filólaques, e Escafa, que outrora viveu as agruras da vida da mulher que precisa se prostituir para sobreviver, vêm à tona aspectos concernentes tanto ao modo de vida das meretrizes representado nas comédias de Plauto e Terêncio, como aos estratagemas que esse tipo cômico emprega em suas artimanhas.

\section{Cena 3, ato 1: a cena do espelho}

Antes de tratar mais detidamente da cena que escolhemos cotejar, em que figuram Escafa e Filemácia, vejamos, em resumo, o plano de Tranião, ludíbrio necessário para contornar os problemas trazidos pelos gastos que Filólaques teve com a jovem meretriz. Dada a longa ausência de seu pai, o velho Teoprópides, Filólaques transforma o patrimônio da família (v. 134-156) em ruínas. Tendo se apaixonado por Filemácia, o adulescens chega a se endividar com um agiota para comprar a liberdade da meretriz (v. 210-211). A vida desregrada de Filólaques seguia bem, até o momento em que Teoprópides regressa inesperadamente (v. 353). Diante da possibilidade de ser pego em flagrante, o jovem, que àquela altura bebia e festejava com Calidamates, seu amigo, e Délfia, a outra meretriz da peça, se desespera (v. 378-381) e pede ajuda a Tranião. O escravo ordena que as meretrizes entrem na casa e lá se mantenham em silêncio (v. 397-402), enquanto ele articula seu ardil. O estratagema de Tranião, como dissemos, consiste em convencer o senex de que Filólaques havia abandonado a casa em que moravam porque o fantasma de um hóspede assassinado pelo antigo proprietário dela havia lhe aparecido em sonho para revelar todo seu infortúnio e avisá-lo da maldição da casa (v. 431-531).

A participação de Filemácia e Escafa, que, depois de entrarem na casa a pedido de Tranião, não retornam mais à cena, inicia-se logo após um extenso monólogo de Filólaques. Ali o jovem, usando uma metáfora que faz o homem equivaler a uma casa, lamenta a ruína de suas estruturas (v. 85-156). Estando no palco, Filemácia e Escafa não sabem, mas a conversa entre elas é ouvida pelo jovem apaixonado, que a todo momento faz apartes ao diálogo espionado. 
Em linhas gerais, a cena é a seguinte. Filemácia entra acompanhada de Escafa, e as duas conversam, enquanto a jovem meretriz se apronta para a chegada de Filólaques. Filemácia está preocupada com sua aparência: ela acaba de se banhar (v. 157-158), pergunta a Escafa se as roupas lhe caem bem (v. 166-167; 172), quer ter certeza de que seus cabelos estão arrumados (v. 254), deseja se maquiar (v. 257 ss.), se perfumar (v. 272) e se olhar no espelho para se enfeitar (v. 248-249). Escafa, por sua vez, se preocupa em aconselhar Filemácia sobre o triste destino das mulheres que vivem como meretrizes. Segundo sua própria experiência, a velha escrava sabe que a sobrevivência de uma prostituta, de um lado, depende do ganho monetário advindo da sua relação com algum homem por ela apaixonado e, por outro lado, está atrelada à juventude dessa mulher.

\section{4. "Espelho, espelho meu": jogo de imagens da meretriz da palliata}

O conteúdo de falas como a de Escafa, em que parece haver um testemunho da difícil realidade da vida de uma mulher na Roma antiga, costuma chamar a atenção dos estudiosos pelo fato de possivelmente refletir condições da vida cotidiana na época de autores como Plauto e Terêncio..$^{10}$ A dificuldade em delimitar o que, de fato, corresponderia à realidade em um texto que não só é literário, mas tem como pano de fundo um ambiente alegadamente grego, com muitas pinceladas romanas, ${ }^{11} \mathrm{é}$

${ }^{10}$ Nesse sentido, cf., por exemplo, a fala da velha escrava Sira n'O Mercador de Plauto sobre a triste vida das mulheres casadas (v. 817-829). Richlin (2015) discute, incluindo entre seus exemplos a mencionada personagem d'O Mercador, a função das ancillae em evidenciar a "verdade" em suas falas. Para uma discussão sobre possíveis interpretações em relação a essa e outras falas femininas sobre o casamento, cf. Rocha (2015, p. 103-106).

${ }^{11}$ Dutsch (2008, p. 2, n. 2) indica exemplos de estudiosos que lidaram com essa tensão presente na fabula palliata. Entre eles, a estudiosa cita Wright (1974), em relação à "dança nas correntes" dos autores desse gênero diante de suas rígidas convenções, e Slater (2000 [1985]), que trata da reação plautina diante das convenções ilusórias do teatro de Menandro, por meio de recursos metateatrais. $O$ tema da ilusão grega na peça romana é abordado em estudo de Cardoso (2010), que remete a uma inteligente abordagem de Moore (1998), sobre ilusão e engano. 
um dos motivos que costuma inibir leituras mais centradas em aspectos sociais ou históricos. ${ }^{12}$

Julgamos, assim, mais profícuo determo-nos em aspectos relacionados à representação dos diferentes comportamentos convencionais que o tipo específico das meretrizes costuma ter no palco da palliata. Há aqui, na nossa opinião, um jogo, por vezes sutil, que envolve dois elementos. De um lado, estão as imagens (sejam reais ou imaginárias) desse personagem-tipo que as meretrizes da peça, Filemácia e Escafa, têm para si. De outro lado, está o modo como as duas personagens planejadamente fazem vir à tona cada uma dessas imagens em seus discursos. Implicado nesse jogo está ainda um duplo movimento que, a nosso ver, aponta tanto para o caráter ilusório do teatro quanto para a materialidade relacionada aos corpos reais dos atores que interpretam essas personagens. ${ }^{13}$ Passemos, então, a tratar mais centralmente da passagem em cotejo.

Filólaques, como dissemos, espiona toda a conversa entre Filemácia e Escafa e reage às falas das duas mulheres, sem que elas, no entanto, tomem conhecimento disso. Essa cena bastante comum no drama, em que uma (ou mais personagens) tem consciência da presença de outras personagens no palco, mas a recíproca não é verdadeira, costuma ser entendida como um recurso metateatral. Trata-se, em linhas gerais, de um momento do drama em que, por meio de uma linguagem, ora mais ora menos direta, sobre o próprio fazer teatral, acena-se para o fato de que a ação dramática é uma convenção entre o mundo do palco e o da plateia. ${ }^{14}$ No caso da cena em questão, os comentários de Filólaques funcionam como uma espécie de apreciação da encenação das meretrizes.

\footnotetext{
${ }^{12}$ Exemplo de um estudo que, procurando lidar com essas limitações, se propõe a tratar da comédia nova grega e romana sob o viés histórico é o de Leigh (2004). Para uma discussão sobre o assunto, sobretudo, quanto ao conceito de gênero, cf. Rocha (2015, p. 27-84). ${ }^{13}$ Ao que sabemos, todos os papéis eram interpretados por homens. Quanto a atores no teatro antigo, cf. o estudo mais geral editado por Easterling e Hall (2002) e, mais especificamente sobre a comédia romana, os estudos de Duckworth $(1952$, p. 76) e de Marshall (2006), com destaque para o segundo capítulo deste último.

${ }^{14}$ Para uma síntese crítica acerca dos estudos metateatrais relacionados ao teatro antigo e, sobretudo, à comédia plautina, cf. Cardoso (2005). Sobre a relação mais específica entre personagens femininas e metateatralidade, cf. Rocha (2015).
} 
Observemos um primeiro exemplo desse tipo de intervenção de Filólaques ao longo da cena que cotejamos nesta discussão. A meretriz, depois de ter se banhado, adentra exultante o palco (v. 157-165) - talvez, nas palavras de Dutsch (2015, p. 26), "em um equivalente teatral de nudez". Filemácia começa a se vestir e pergunta a Escafa se a roupa que está trajando lhe cai bem (v. 166-167). A resposta da velha escrava se baseia numa espécie de conselho:

FILE. Veja, por favor, minha Escafa se essa roupa me cai bem o suficiente. Eu quero agradar Filólaques, meu olhinho, meu protetor. ${ }^{15}$

ESC. Por que você se enfeita com modos encantadores quando você mesma é encantadora? Os apaixonados não amam a roupa [da mulher], mas o que recheia as roupas. ${ }^{16}$ (Mos. 166-9; tradução nossa) ${ }^{17}$

Tendo ouvido a resposta de Escafa, Filólaques reconhece a expertise da escrava sobre o comportamento dos homens apaixonados. O jovem exclama em aparte: "Que os deuses me guardem! Escafa é encantadora. A pilantra é muito sabida! Como conhece bem todos os costumes e pensamentos dos apaixonados!". ${ }^{18}$ Como espectador, o adulescens aprecia a boa atuação de Escafa. Filólaques admite que a

${ }^{15}$ Patrono (v. 167): o termo patronus designa, segundo o sentido 1a do $O L D$ (que inclui esta passagem plautina), "uma pessoa influente que assumiu a proteção de outra pessoa, um patrono" ("an influential person who has undertaken the protection of another person, a patron"; tradução nossa). Como aponta Terzaghi (PLAUTO, 1929, p. 3), Filólaques torna-se patrono de Filemácia ao comprar sua liberdade, e, com isso, obtém sua manumissão (cf. verso 1 do argumento).

${ }^{16}$ Sonnenschein (PLAUTI, 1907, p. 84) indica passagem com teor semelhante em Poen. $306 \mathrm{~s}$.

${ }^{17}$ Seguimos a edição de Ernout para a coleção da Belles Lettres (PLAUTE, 2003). O texto latino referente ao trecho citado é este: PHILE. Contempla, amabo, mea Scapha, satin haec me uestis deceat./ Volo me placere Philolachi, meo ocello, meo patrono./ SC. Quid tu te exornas, moribus lepidis quom lepida tute es?/ Non uestem amatores amant [mulieris], sed uestis fartim.

${ }^{18}$ PHILO. Ita me di ament, lepida $<$ st $>$ Scapha; sapit scelesta multum./ Vt lepide omnis $<$ mo $>$ res tenet sententiasque amantum! 
escrava sabe como se comportam os jovens apaixonados do palco da palliata. Ou seja, Escafa sabe o que dizer e como se portar para agradar tal tipo cômico. Também o público, afeito aos enredos plautinos, reconheceria nessa passagem a dinâmica entre jovens apaixonados e suas amadas, representada tantas vezes no palco da comédia nova.

Gostaríamos de destacar ainda outro aspecto do comentário da escrava para o qual, ao que nos consta, ainda não se chamou atenção. Trata-se do efeito de haver ali, a nosso ver, uma alusão ao corpo do ator que interpreta a meretriz. Parece-nos que a fala da escrava - afirmando que o que importa aos apaixonados não são as vestes, mas sim aquilo que elas contêm - joga luz sobre dois aspectos. O primeiro, explicitado textualmente, é o fato de que os jovens se interessam, na realidade, sobre o corpo da mulher. Mas, além disso, ao chamar a atenção para as vestes, a fala de Escafa pode destacar o fato de que Filemácia é interpretada por um homem; afinal quem, no palco, preenche as elogiadas vestes é o ator. Dessa maneira, pode haver aqui, para os que se apercebem da alusão ao elemento cênico, um rompimento da ilusão teatral, que, ainda que momentâneo, poderia abrir espaço para uma brincadeira de cunho sexual. Reconhecida pelo público a sutil alusão ao patente desvio entre a figura vista (um homem atuando como meretriz) e aquilo que ela representa para o público (uma bela jovem meretriz) - seja interno, seja externo à peça-, possivelmente seria maior o efeito cômico da concordância de Filólaques com a fala de Escafa. ${ }^{19}$

A empiria de Escafa, no entanto, nem sempre é bem-vinda na apreciação do jovem apaixonado. Na sequência do diálogo, conforme a escrava começa a manifestar seu conhecimento sobre a vida de outro tipo de personagem, Filólaques vai mudando de opinião:

\footnotetext{
${ }^{19}$ Desvio semelhante é explorado em outras peças de Plauto de modo mais direto. Em Cásina, por exemplo, temos uma falsa noiva, a escrava que dá título à peça. Trata-se, na verdade, do escravo Calino travestido. A discrepância entre o gênero do ator e a personagem que ele representa - diferença inescapável, que, nessa peça, é explorada propositadamente - é mote para muitas das brincadeiras sexuais presentes no enredo. Um exemplo é a cena em que a escrava Pardalisca narra ao velho Lisidamo a loucura da (suposta) escrava Cásina (v. 621-719). Sobre aspectos metateatrais em Cásina, cf. Williams (1993); Plauto (2013).
} 
ESC. De fato, por Pólux, me admira que você tão esperta, tão ilustrada e tão bem ilustrada, agora se faça de tonta tontamente.

FILE. Vamos, aconselhe-me, por favor, se estou errando em algo.

ESC. Você, por Castor, está errando ao, de fato, ficar esperando apenas ele e assim só fazer o que ele quer e, com isso, repelir os outros homens. Ficar presa a um único amor é coisa de matrona, não de meretriz. $<190>$

FILO. Por Júpiter! Que tipo de mal é esse que está se apossando da minha casa? Que todos os deuses e deusas me arruínem com os piores castigos se eu não matar essa escrava de fome, de sede e de frio! (Mos. 186-193; tradução nossa $)^{20}$

Como vemos, quando Escafa alerta Filemácia sobre a possibilidade de ela ser abandonada pelo jovem a quem está dedicando toda sua devoção, Filólaques a reprova e lhe promete um castigo. Aqui está em jogo a atuação dos dois tipos de meretrizes da palliata. De um lado, a experiente Escafa procura convencer Filemácia do risco de se prender a um único homem uma única fonte de renda; ${ }^{21}$ de outro, Filemácia, a jovem meretriz, parece estar entregue à paixão. A consciência do público acerca da relação entre jovens e meretrizes, o qual, tendo assistido a outras comédias, reconheceria no diálogo a alusão a tipos convencionais da palliata, poderia corroborar uma ridicularização da posição de Filólaques.

${ }^{20}$ SC. Equidem pol miror tam catam, tam $^{+}$doctam $^{+}$te et bene doctam/ Nunc stultam stulte facere. PHILE. Quin mone, quaeso, si quid erro./ SC. Tu ecastor erras, quae quidem illum expectes unum atque illi/ morem praecipue sic geras, atque alios aspernere./ Matronae, non meretricium est unum inseruire amantem. <190>/ PHILO. Pro Iuppiter, nam quod malum uersatur meae domi illud?/ Di deaeque me omnes pessumis exemplis interficiant, / Nisi ego illam anum interfecero siti fameque atque algu. ${ }^{21}$ Conselhos de teor semelhante profere Sira a Filotes em Hecyra, peça de Terêncio (Hec. 58-75). Em comentário a referida passagem da comédia terenciana, Goldberg (TERENCE, 2013, p. 96) lembra-nos de que cenas em que uma meretriz mais velha aconselha uma mais jovem fazem parte do repertório da comédia nova, citando esta passagem de Mostellaria e passagens de outras peças plautinas (cf. Asin. 504-44; Cist. 78-81). Quanto ao alegado discurso misógino reproduzido por Sira e seu efeito na peça de Terêncio, cf. Bragion (2016, p. 57-87). 
Na sequência, Escafa continua tentando dissuadir Filemácia de sua entrega total ao adulescens:

FILE. Eu não quero que você me aconselhe mal, Escafa.

ESC. Você é absolutamente tola se pensa que ele será eternamente benevolente e apaixonado. $<195>\mathrm{Eu}$ estou avisando: ele vai lhe deixar quando você envelhecer e ele se encher.

FILE. Espero que não.

ESC. As coisas inesperadas acontecem mais vezes do que as que se espera. No fim, se você não pode se convencer pelo que foi dito a ponto de acreditar que é verdade o que eu disse, saiba da situação a partir dos fatos. Você está vendo quem eu sou. E quem eu era antes! Não fui menos amada do que você agora. E eu, então, fiz só o que queria um único homem $<200>$ que, por Pólux, quando envelheci e este cabelo mudou de cor, me abandonou e me deixou. Acredito que você terá o mesmo futuro. (Mos. 194-202; tradução nossa.) ${ }^{22}$

Mais uma vez, Escafa se vale do seu conhecimento empírico sobre a vida de uma meretriz no palco da palliata: ela sabe que o alegado amor do rapaz apaixonado se vai conforme a idade da jovem avança e sua aparência já não é tão bela. ${ }^{23}$ Em suas palavras, ela mesma é a imagem do que acontece à mulher que depende da sua juventude para extrair dinheiro dos homens. ${ }^{24}$

${ }^{22}$ PHILE. Nolo ego mihi male te, Scapha, praecipere./ SC. Stulta es plane,/ Quae illum tibi aeternum putes fore amicum et beneuolentem. $<195>/$ Moneo ego te : te ille deseret aetate et satietate./ PHILE. Non spero. SC. Insperata accidunt magis saepe quam quae speres./ Postremo, si dictis nequis perduci, ut uera haec credas/Mea dicta, ex factis nosce rem. Vides quae sim; et quae fui ante!/ Nihilo ego quam nunc tu amata sum; atque uni modo gessi morem, $<200>/$ Qui pol me, ubi aetate hoc caput colorem commutauit,/ Reliquit deseruitque me. Tibi idem futurum credo.

${ }^{23}$ Rosivach (1998, p. 5), em seu estudo sobre a exploração sexual das mulheres na comédia nova, sintetiza essa realidade: "quando um desses jovens se apaixona, ele se apaixona pelo aspecto físico da jovem mulher" ("when one of these young men falls in love, what he falls in love with is the physical appearance of the young woman"; tradução nossa). ${ }^{24}$ Afirmação de teor semelhante é proferida por Báquide em Heautontimoroumenos (Hau. 389-95). 
Filemácia tenta rebater o argumento de Escafa. A meretriz afirma ter motivos para justificar sua dedicação a Filólaques:

FILE. Ele, só eu, só para si, com seu próprio tesouro libertou. Só a ele julgo conveniente [apenas] eu ser obediente. $<205>$ $[\ldots]$

ESC. Você está livre. Já tem o que você desejava. Ele, se não continuar amando você mais tarde, $<210>$ terá perdido o tanto de dinheiro que deu pela sua liberdade. (Mos. 204205; 209-211; tradução nossa. $)^{25}$

Segundo a alegação da jovem meretriz, é o fato de sua liberdade ter sido comprada por Filólaques que a faz lhe ser obediente. Mas na avaliação da experiente escrava não há motivos para que Filemácia seja leal ao jovem, uma vez que já está livre. A importância da passagem do tempo no tipo de relação que se estabelece entre um adulescens e uma meretrix continua sendo apontada por Escafa:

FILE. Eu nunca serei capaz de agradecê-lo como é devido. Escafa, não venha me convencer a ter menor consideração por ele.

ESC. Mas peço que você pense apenas nisto: se você vai ficar presa apenas a ele agora enquanto é jovenzinha, na velhice, você se arrependerá.

$[\ldots]$

FILE. Convém que agora, que consegui o que me agrada, eu tenha a mesma afeição, $<220>$ quando outrora, antes de eu arrancar isso dele, o cobria com palavras doces. (Mos. 214-217; 220-221; tradução nossa) $)^{26}$

${ }^{25}$ PHILE. Solam ille me soli sibi suo < sumptu> liberauit :/ [Solam] Illi me soli censeo esse oportere opsequentem. [...] SC. Inscita ecastor tu quidem es. PHILE. Quapropter? SC. Quae istuc < cures>,/Vt te ille amet. PHILE. Cur obsecro non curem? SC. Libera es iam./Tu iam quod quaerebas habes: ille te nisi amabit ultro, $<210>/$ Id pro tuo capite quod dedit perdiderit tantum argenti.

${ }^{26}$ PHILE. Numquam ego illi possum gratiam referre, ut meritust de me./Scapha, id tu mihi ne suadeas, ut illum minoris pendam. $<215>/$ SC. At hoc unum facito cogites : si illum inseruibis solum/ Dum tibi nunc haec aetatulast, in senecta male querere. [...] PHILE. Eundem animum oportet nunc mihi esse gratum, ut inpetraui, $<220>/$ Atque olim, priusquam id extudi, quom illi subblandiebar. 
Como vemos, ao aconselhar Filemácia a não se prender ao jovem no atual momento, a argumentação de Escafa está novamente centrada na oposição entre duas fases da vida da meretriz: a juvenil - e, consequentemente, bela - e a senil - em que seu aspecto físico não atrai mais os homens. A lógica de Filemácia, no entanto, contrapõe outros dois momentos da sua relação com Filólaques, cujo divisor é a compra de sua liberdade pelo jovem. Se agora a meretriz pretende se mostrar em harmonia com o adulescens, outrora, para atingir seus objetivos, ela adotara estratégia tida como típica das mulheres na comédia nova: o emprego de "palavras doces" (subblandiebar; v. 221). ${ }^{27}$

Mesmo os comentários de Élio Donato ( $f .353$ d.C.) às peças de Terêncio, datados do século IV d.C. (ou seja, com um lapso temporal de 600 anos depois da escrita e encenação das peças de Plauto), chamam atenção para a fala melíflua atribuída às mulheres em geral. ${ }^{28}$ Segundo o comentarista, o comportamento linguístico típico das personagens femininas teria três características: aliis blandiri ("dirigir-se aos outros de maneira persuasiva"); se commiserari ("apiedar-se de si mesma") e tardiloquium ("prolixidade"). ${ }^{29}$ Embora essa possa ser uma característica mais geral, não é incomum que ela seja atribuída exclusivamente à (vil) estratégia discursiva das meretrizes. Em Cásina, por exemplo, a matrona Cleóstrata, ao ouvir o marido, Lisidamo, reclamar de que ela não o tratava com a doçura necessária, protesta imediatamente: "Maridinho, cobrir de conversas doces os maridos alheios não é tarefa de matrona, mas sim de meretriz" (Cas. 585-6, tradução nossa.). ${ }^{30}$

A fala de Filemácia coloca em evidência sua consciência sobre a capacidade de agir como uma meretriz gananciosa, quando isso the interessa. Ou seja, ainda que agora atue como uma jovem inexperiente

${ }^{27}$ Como aponta Collart (PLAUTUS, 1970, p. 61), o verbo subblandior, derivado de blandior, parece ter sido invenção plautina. Cf. Bac. 517; Cas. 585.

${ }^{28}$ Para um levantamento mais extensivo de passagens de autores da Antiguidade sobre o modo como as mulheres falariam, com bibliografia sobre o tema, cf. Fögen (2004). ${ }^{29}$ Sobre a existência de um discurso tipicamente feminino na comédia palliata, cf. Adams (1984); Schauwecker (2002); Dutsch (2008); Rocha (2015).

${ }^{30}$ CLE. Non matronarum officiumst, sed meretricium, $<585>/$ Viris alienis, mi uir, subblandirier. Sobre a fala blanda das meretrizes, cf. Rocha (2015, p. 80-84). 
e passiva em relação à vontade de Filólaques, a meretriz conhece o papel de uma mala meretrix, em outros tempos por ela desempenhado. A menção às intenções de Filemácia não só tornam o comportamento de Filólaques ainda mais ridículo - por dedicar seus bens a uma meretriz -, como convencem Escafa, que encerra seu ponto de vista com a seguinte afirmação: "Se você admitiu que terá sustento perpétuo e que esse amor será só seu a vida toda, acredito que você deva fazer o que ele quer e usar o cabelo preso"31 (Mos. 224-6, tradução nossa.). ${ }^{32}$

Neste diálogo ocorre ainda algo que gostaríamos de destacar. Há aqui certa insistência das personagens em ações relacionadas ao olhar, chamando atenção para aspectos físicos do espaço teatral. No primeiro trecho que analisamos nesta seção, Filemácia pede a opinião de Escafa sobre suas roupas, pedindo que a escrava olhe para ela (contempla; v. 166). Adiante, Filemácia insiste: "Vai, olhe para mim e veja como essa roupa me cai" (Quin me aspice et contempla ut haec me dece<a>t.; Mos. 172; tradução nossa, grifos nossos). Os pedidos da meretriz versam não só sobre sua aparência, mas sobre seus trajes, dando inevitável destaque a um aspecto mais material do palco da comédia. ${ }^{33}$

Conforme o diálogo avança, situações semelhantes se repetem. Há, contudo, em nossa opinião uma crescente abstração em relação à imagem que deve ser "vista" pelas personagens em cena. Vejamos a passagem sobre a qual comentamos anteriormente, agora sob outro enfoque. Ao aconselhar Filemácia quanto aos efeitos do inevitável envelhecimento sobre a vida de uma meretriz, Escafa insiste no sentido da visão relacionado à percepção de sua atual situação: "Você está vendo quem eu sou. E quem eu era antes! Não fui menos amada do que você

${ }^{31}$ Capiundas crines (v. 226): crinis significa literalmente "trança". Segundo os editores, a referência aqui é ao penteado de uma matrona, que trazia os cabelos trançados (cf. PLAUTUS, 1970, p. 62; PLAUTI, 1907, p. 89). O termo também é registrado nos versos 791-792 da peça Miles gloriosus, num momento em que uma meretriz vai ser disfarçada de matrona.

${ }^{32}$ SC. Si tibi sat acceptum est fore tibi uictum sempiternum,/ Atque illum amatorem tibi proprium futurum in uita, <225>/ Soli gerundum censeo morem et capiundas crines. ${ }^{33}$ Sobre o uso de trajes na comédia nova romana, cf. Beare (1964, p. 184-195); Marshall (2006, p. 56-66). 
agora." (Vides quae sim; et quae fui ante!/ Nihilo ego quam nunc tu amata sum; Mos. 199-200; tradução nossa, grifos nossos). A ordem da escrava projeta em si uma espécie de espelho, no qual a jovem meretriz veria seu momento atual e também seu futuro. ${ }^{34}$ Por um lado, a aparência física de Escafa (e do ator que a interpreta) é única - e permite que seu "antes" seja apenas vislumbrado. Por outro lado, contudo, podemos pensar que se chama atenção aqui para as múltiplas facetas do tipo da meretriz que parecem estar em jogo no diálogo entre as personagens.

Na sequência, elementos materiais são acrescentados à cena. O espelho, antes abstrato, passa a ser real: Filemácia pede que Escafa traga um espelho e enfeites para que ela se apronte para a chegada de Filólaques:

FILE. Escafa, me dê o espelho e a caixinha com os enfeites imediatamente, para eu me enfeitar para quando Filólaques, minha delícia, chegar.

ESC. A mulher que desdenha de si mesma e da sua idade é que precisa de um espelho. $<250>$ De que serve um espelho a você, que é o melhor espelho para um espelho? (Mos. 248251 ; tradução nossa) ${ }^{35}$

A resposta da escrava, que parece condenar o pedido da meretriz, insiste na noção de um espelhamento abstrato. Nesse sentido, concordamos com Dutsch $(2015$, p. 28), que afirma que a sugestão de Escafa é de que Filemácia não precisa se pautar em sua imagem no espelho porque ela é seu próprio modelo. Em termos linguísticos, a insistência nas formas de segunda pessoa (tibi e tute; este acrescido da partícula de reforço

${ }^{34}$ Dutsch (2015, p. 27, tradução nossa.) afirma que esse processo de espelhamento começa já nos pedidos de Filemácia para que Escafa olhe para ela: "ao pedir com insistência que Escafa olhe para ela e opine sobre sua aparência, Filemácia, na verdade, pede que a velha haja como um medíocre espelho vivo." ("In requesting repeatedly that Scapha look at her and critique her appearance, Philematium in fact asks the old woman to act as living mirror of sorts"; tradução nossa).

${ }^{35}$ PHILE. Cedo mi speculum et cum ornamentis arculam actutum, Scapha, / Ornata ut sim, quom huc <ad>ueniat Philolaches uoluptas mea./ SC. Mulier quae se suamque aetatem spernit, speculo ei usu $<s>$ est: $<250>/$ Quid opust speculo tibi, quae tute speculo speculum es maxumum? 
-te; Mos. 251) parecem enfatizar essa ideia. A argumentação de Escafa segue no sentido de defender que a imagem atual da jovem meretriz não precisa de reparos. Filemácia pede o "pó"36 e depois o "blush" 37 . A todos os pedidos, a escrava responde negativamente, procurando convencer Filemácia de que aquilo é desnecessário.

Há aqui, uma vez mais, uma duplicidade na "imagem" para a qual se chama atenção. Por um lado, Escafa pode remeter a adequação de Filemácia a seu papel. Mas, por outro lado, a insistência para que a meretriz não altere sua aparência pode colocar em destaque, de maneira irônica a nosso ver, o quão adequado está em seu papel o ator que interpreta a personagem, aludindo-se, inclusive, à divergência entre o gênero da personagem e do ator. ${ }^{38}$

\section{Palavras finais: reflexos do speculum de Filemácia}

Por fim, para o entendimento da cena cotejada neste artigo, julgamos ser ainda relevante lançar mão de uma discussão sobre os momentos em que a consciência das personagens sobre aspectos relacionados às convenções teatrais, como o que discutimos anteriormente, parece ser explicitada ao público. O efeito desse recurso é entendido de maneira diversa pelos estudiosos. Niall Slater, por exemplo, em seu seminal estudo de 1983, Plautus in performance - the theatre of the mind, inclui entre as "convenções não ilusórias" atos como o de espionar, o de fazer apartes - assim como faz Filólaques - e os momentos de peçadentro-da peça, em que a ação teatral se distanciaria da verossimilhança em relação à vida da plateia (SLATER, 2000 [1983], p. 8 ss.). Ou seja, na opinião do estudioso, esse uso da metalinguagem em vez de contribuir para a manutenção do pacto que existe entre plateia e palco (e permite que uma peça aconteça) acaba por romper a ilusão teatral. Assim, a

\footnotetext{
${ }^{36}$ No original, cerussam (v. 258), um pigmento branco aplicado sobre a face.

${ }^{37}$ Purpurissum (v. 261) é, segundo o OLD, terra tingida com pigmento tírio, usada como um cosmético.

${ }^{38}$ Dutsch (2015, p. 28-29), considerando um breve histórico de referências a imago no teatro plautino, sugere interpretação divergente, baseada na ideia de que se propõe aqui uma conscientização de Filemácia sobre seu eadem quae.
} 
divergência entre as visões que cada uma das personagens em cena tinha sobre si mesma e sobre as demais quando expressas como alusão às diferentes caracterizações das meretrizes na palliata, como tentamos expor acima, teria como efeito a suspensão da ilusão dramática, como que numa lembrança à plateia de que aqueles são apenas personagens interpretados por atores. Ainda que essa pareça ser a situação em algumas das passagens discutidas, gostaríamos de apontar possibilidade diferente em outros casos.

Nesse sentido, preferimos a interpretação de Cardoso (2005, 2010), que, revendo a posição do estudioso americano, sugere que esse tipo de situação, ainda que não imite a vida real, faria parte das expectativas do público familiarizado com a comédia nova, ou até mesmo, com o anterior teatro itálico. Dessa maneira, uma passagem que demonstrasse o conhecimento das personagens sobre a ilusão teatral contribuiria não para um rompimento da ilusão, mas sim para a criação de uma nova camada de ilusão dramática dentro do ambiente teatral.

Como procuramos mostrar, parecem estar em jogo, ao menos nessa cena de Mostellaria, os efeitos do reconhecimento, seja por parte das personagens, seja por parte do público, dos comportamentos típicos das meretrizes. Aliada a este aspecto, a presença de duas personagens femininas em cena num diálogo em que a aparência das mulheres é mote para a discussão sobre o destino de uma meretriz parece ensejar o destaque para outro aspecto cênico: o corpo dos atores. Assim, para o público que adentra essa nova camada ilusória, resultante da alusão a tais aspectos, afeta-se a percepção não só da ação de tais personagens, como também sua relevância para o desenrolar da peça. Desse modo, sendo conhecedor do jogo entre as diferentes nuanças dos personagens e plots típicos do palco palliata, a plateia - a quem pouco importa o que reflete o espelho de Filemácia - usufruiria da habilidade e do humor plautino. Talvez sejam seus reflexos turvos refletidos no espelho da comédia nova romana que têm feito o público rir ainda nos dias de hoje. 


\section{Referências}

ADAMS, J. N. Female Speech in Latin Comedy. Antichthon, Cambridge, v. 18, p. 43-77, 1984. DOI: https://doi.org/10.1017/S0066477400003142. ADAMS, J. N. Words for "Prostitute" in Latin. Rheinisches Museum für Philologie, Neue Folge, Köln, v. 126, n. 3/4, p. 321-358, 1983.

BEARE, William. The Roman Stage: A Short History of Latin Drama in the Time of the Republic. 3. ed. Londres: Methuen, 1964.

BRAGION, Aline S. L. A fuga da sogra: mulheres, poesia e humor em Hecyra. 2016. 251f. Dissertação (Mestrado em Linguística) - Instituto de Estudos da Linguagem, Universidade Estadual de Campinas, Campinas, 2016. Disponível em: http://repositorio.unicamp.br/jspui/bitstream/ REPOSIP/320927/1/Bragion_AlinedaSilvaLazaro_M.pdf. Acesso em: 27 maio 2020.

CARDOSO, Isabella T. Ars plautina. 2005. 367f. Tese (Doutorado em Letras Clássicas) - Faculdade de Filosofia, Ciências e Letras, Universidade de São Paulo, São Paulo, 2005.

CARDOSO, Isabella T. Estico de Plauto. Campinas: Editora da Unicamp, 2006.

CARDOSO, Isabella T. Ilusão e engano em Plauto. In: CARDOSO, Zélia de A; DUARTE, Adriane da S. (org.). Estudos sobre o teatro antigo. São Paulo: Alameda, 2010. p. 95-126.

DUCKWORTH, George E. The Nature of Roman Comedy: A Study in Popular Entertainment. Princeton, NJ: Princeton University Press, 1952.

DUTSCH, Dorota M. Feats of Flesh: the Female Body on the Plautine Stage. In: DUTSCH, Dorota; JAMES, Sharon L.; KONSTAN, David (ed.). Women in Roman Republican Drama. Wisconsin: The University of Wisconsin Press, 2015. p. 17-36.

DUTSCH, Dorota M. Feminine Discourse in Roman Comedy: On Echoes and Voices. Oxford: Oxford University Press, 2008. DOI: https://doi. org/10.1093/acprof:oso/9780199533381.001.0001.

DUTSCH, Dorota; JAMES, Sharon L.; KONSTAN, David (ed.). Women in Roman Republican Drama. Wisconsin: The University of Wisconsin Press, 2015. 
EASTERLING, Pat; HALL, Edith (ed.). Greek and Roman Actors: Aspects of an Ancient Profession. Cambridge: Cambridge University Press, 2002.

FERREIRA, Caroline B. F. Reconstrução de uma cortesã na Roma antiga nas peças de Plauto. 2013. 90f. Dissertação (Mestrado em Letras) - Universidade Federal do Espírito Santo, Vitória, 2013. Disponível em: http://portais4.ufes.br/posgrad/teses/tese_6153 DISSERTA $\%$ C $7 \%$ C2O $\% 20$ COMPLETA $\% 20-\% 20$ CAROLINE $\% 2 \overline{0}$ BARBOSA.pdf. Acesso em: 27 maio 2020.

FÖGEN, Thorsten. Gender Specific Communication in Graeco-Roman Antiquity. With a Research Bibliography. Historiographia Linguistica, Amsterdam, v. 31, p. 199-276, 2004.

HUNTER, Richard L. The New Comedy of Greece and Rome. Cambridge: Cambridge University Press, 1989.

KEMPER, Sjef. Docendi facultas: la retorica dello spettro nella Mostellaria di Plauto. In: RAFFAELLI, Renato; TONTINI, Alba (org.). Lecturae Plautinae Sarsinates XIII. Mostellaria. Sarsina, 29 set. 2009. Urbino: QuattroVenti, 2010. p. 31-57.

LEIGH, Matthew. Comedy and the Rise of Rome. Oxford: Oxford University Press, 2004. DOI: https://doi.org/10.1093/acprof:o so/9780199266760.001.0001.

MANUWALD, Gesine. Roman Republic Theatre. Cambridge: Cambridge University Press, 2011.

MARSHALL, Christopher W. The Stagecraft and Performance of Roman Comedy. Nova York: Cambridge University Press, 2006. DOI: https://doi. org/10.1017/CBO9780511486203.

MOORE, Timothy. The Theater of Plautus: Playing to the Audience. Austin: Texas University Press, 1998.

PACKMAN, Zola M. Feminine Role Designations in the Comedies of Plautus. The American Journal of Philology, Baltimore, MD, v. 120, n. 2, p. 245-258, Summer 1999. DOI: https://doi.org/10.1353/ajp.1999.0027.

PLAUTE. Comédies. Mostellaria - Persa - Poenulus. Texto estabelecido e traduzido por Alfred Ernout. 4. ed. Paris: Les Belles Lettres, 2003. Tomo V. 
PLAUTI, T. MACCI. Mostellaria. Edição e notas de Edward A. Sonnenschein. 2. ed. Oxford: Clarendon Press, 1907.

PLAUTO, T. Maccio. La Mostellaria. Introdução, texto crítico e comentário de Nicola Terzaghi. Torino: G. B. Paravia, 1929.

PLAUTO. A comédia do fantasma ('Mostellaria'). Tradução, introdução e comentário de Reina Marisol Troca Pereira. Coimbra; São Paulo: Imprensa da Universidade de Coimbra; Annablume Editora, 2014.

PLAUTO. Cásina. Introdução, tradução e notas de Carol Martins da Rocha. Campinas: Mercado de Letras, 2013.

PLAUTUS, T. M. Mostellaria. Edição, introdução e comentário de Jean Collart. Paris: Presses Universitaires de France, 1970.

PLAUTUS. Bacchides. Edição com tradução e comentários de John Barsby. 3. ed. Wiltshire: Aris \& Phillips Ltd, 1991.

PLAUTUS. Stichus. Introdução, edição e comentário de Hubert Petersmann. Heidelberg: Carl Winterverlag, 1973.

RICHLIN, Amy. Slave-woman drag. In: DUTSCH, Dorota; JAMES, Sharon L.; KONSTAN, David (ed.). Women in Roman Republican Drama. Wisconsin: The University of Wisconsin Press, 2015. p. 37-67.

ROCHA, Carol M. da. De linguado a lingua(ru)da: gênero e discurso das mulieres plautinae. 2015. 251f. Tese (Doutorado em Linguística) Universidade Estadual de Campinas, Campinas, 2015. Disponível em: http://www.repositorio.unicamp.br/handle/REPOSIP/270792. Acesso em: 27 maio 2020.

ROSIVACH, Vincent J. When a Young Man Falls in Love: The Sexual Exploitation of Women in New Comedy. Londres; Nova York: Routledge, 1998.

TERENCE. Hecyra. Edição e comentários de Sander M. Goldberg. Cambridge: Cambridge University Press, 2013. DOI: https://doi. org/10.1017/CBO9781139021593.

SCHAUWECKER, Y. Zum Sprechverhalten der Frauentypen bei Plautus. Gymnasium: Zeitschrift für Kultur und humanistische Bildung. Edição de Franz Bömer e Ludwig Voit, 2002. v. 109, p. 191-211. 
SLATER, Niall W. Plautus in Performance: The Theatre of the Mind. 2. ed. Amsterdã: Harwood Academic Publishers, 2000.

WILliAMS, B. Games People Play: Metatheatre as Performance Criticism in Plautus' Casina. Ramus, Cambridge, v. 22, n. 1, p. 35-59, 1993. DOI: https://doi.org/10.1017/S0048671X00002538.

WITZKE, Serena S. Harlots, Tarts, and Hussies?: A Problem of Terminology for Sex Labor in Roman Comedy. Helios, Lubbock, v. 42, n. 1, p. 7-27, Spring 2015. DOI: https://doi.org/10.1353/hel.2015.0000. WRIGHT, John. Dancing in Chains: The Stylistic Unity of the comoedia palliata. Roma: American Academy in Rome, 1974. (Papers and Monographs of the American Academy in Rome).

Recebido em: 28 de maio de 2020. Aprovado em: 30 de setembro de 2020. 